\title{
Friction and wear behavior of electro-deposition Ni-cBN composite coatings
}

\author{
Xin $\mathrm{Gao}^{1, \mathrm{a}}{ }^{*}$, Ying Liu ${ }^{1, \mathrm{~b}}$, Xiuchen Zhao ${ }^{1, \mathrm{c}}$ and Chenyi Dai ${ }^{1, \mathrm{~d}}$ \\ ${ }^{1}$ Department of Materials Science and Engineering, Beijing Institute of Technology, Beijing 100081, \\ China \\ a18813046254@163.com, byingliu@bit.edu.cn, czhaoxiuchen@bit.edu.cn, ${ }^{\mathrm{a}} \mathrm{zjkhdcy@126.com}$
}

Keywords: Titanium alloy; Electroplating; Cubic boron nitride; Friction and wear; composite Abstract: In this paper, Ni-cubic boron nitride (cBN) composite coating with different volume fractions (from 0.3 to $8.5 \mathrm{vol} . \%$ ) of $\mathrm{cBN}$ particle was successfully prepared by electro-deposition method on titanium alloy substrates. The effect of volume fraction of cBN particles and applied load on the friction and wear behaviors of the composite coatings were investigated at a speed of 0.0333 $\mathrm{m} \cdot \mathrm{s}^{-1}$. The experimental results indicate that the friction coefficient of the composite coatings decreased with increasing the volume fraction of cBN particles and the applied load. Moreover, within the range of volume fraction of $\mathrm{cBN}$ particles from 0 to $8.5 \%$, the wear rate of the composite coatings showed a decreasing trend from 0.2417 to $0.0267 \mathrm{mg} \cdot \mathrm{m}^{-1}$ with increasing volume of $\mathrm{cBN}$ particles. The wear rate of the composite coating increased with the increase of the applied load.

\section{Introduction}

Recnetly, Ti-6Al-4V (TC4) alloy has been paid more and more attention due to its high strength, low density, and good corrosion resistance [1-4]. However, the low wear performances has restricted its further practical application in certain field, such as aerospace. To our best knowledge, surface treatment method is widely used to improve the wear resistance of the Ti alloys, such as physical vapor deposition (PVD)[5], chemical vapor deposition (CVD)[6], electroless plating[7] and electroplating[8]. Compared to other medhods, Electro-deposition is one of the most important techniques for producing composites of metallic and non-metallic constituents, because of its simple process and fast deposition rate. Coatings containing solid particles such as $\mathrm{SiC}, \mathrm{Al}_{2} \mathrm{O}_{3}, \mathrm{WC}, \mathrm{CNT}$ and diamond, etc. have been developed for better wear resistance or dispersion hardening [9-14]. Cubic boron nitride (cBN) has outstanding physical and chemical properties similar to diamond such as high hardness, high thermal conductivity, large band gap, and high breakdown field [15-17]. So cubic boron nitride (cBN) particles are chosen as the second phase to enhance the wear resistance property of the coating.

In this paper, Ni-cBN composite coatings with different volume fractions of $\mathrm{cBN}$ particles were deposited on titanium alloy by electroplate. The effect of the volume fraction of $\mathrm{cBN}$ particles and applied load on friction and wear properties of the Ni-cBN composite coatings were investigated.

\section{Experimental}

\section{Preparation of Ni-cBN composite coating}

The commercialized TC4 titanium alloy was used as the substrate with the size of $18 \mathrm{~mm} \times 12$ $\mathrm{mm} \times 8 \mathrm{~mm}$. The TC4 titanium alloy substrate had the composition of $5.5 \% \sim 6.8 \% \mathrm{Al}, 3.5 \% \sim 4.5 \% \mathrm{~V}$ with the balance of $\mathrm{Ti}$ (wt.\%). Before preparation of coatings, the TC4 titanium alloy was ground up to a grit of \#600 using SiC papers, and then ultrasonically cleaned in acetone for 5 min. The pre-treatment process of the TC4 titanium alloy included washing in an alkaline solution containing 60 80 g/L NaOH, 20 40 g/L Na $2 \mathrm{CO}_{3}, 20 \sim 40 \mathrm{~g} / \mathrm{L} \mathrm{Na}_{3} \mathrm{PO}_{4}$ and $3 \sim 10 \mathrm{~g} / \mathrm{L} \mathrm{Na}_{2} \mathrm{SiO}_{3}$ at $70{ }^{\circ} \mathrm{C}$ for $30 \mathrm{~min}$, and activating in a solution containing $50 \mathrm{~mL} / \mathrm{L} \mathrm{HCl}$ and $40 \mathrm{~mL} / \mathrm{L}$ HF at room temperature for $1 \sim 3$ min, and finally washing thoroughly with distilled water before conducting the plating, as shown in Table 1. After pre-treatment, a double-layered Ni/Ni-cBN coating was prepared on the TC4 titanium 
alloy substrate, that is, the Ni coating was firstly electroplated on the TC4 titanium alloy, and then the Ni-cBN composite coating was electroplated as the outmost layer. Washing was conducted in distilled water for a short duration of less than 30s after the $\mathrm{Ni}$ and $\mathrm{Ni}-\mathrm{cBN}$ layers were plated, respectively. The detailed electro-deposition parameters and process are also shown in Table 1.

Table. 1 The pre-treatment and electro-deposition processes of the TC4 titanium alloy.

\begin{tabular}{llll}
\hline Process & $\mathrm{Chemicals}$ & Concentration & Conditons \\
\hline \multirow{4}{*}{ Alkaline cleaning } & $\mathrm{NaOH}$ & $60-80 \mathrm{~g} / \mathrm{L}$ & \\
& $\mathrm{Na}_{2} \mathrm{CO}_{3}$ & $20-40 \mathrm{~g} / \mathrm{L}$ & $70{ }^{\circ} \mathrm{C}, 30 \mathrm{~min}$ \\
& $\mathrm{Na}_{3} \mathrm{PO}_{4}$ & $20-40 \mathrm{~g} / \mathrm{L}$ & \\
& $\mathrm{Na}_{2} \mathrm{SiO}_{3}$ & $3-10 \mathrm{~g} / \mathrm{L}$ & \\
\multirow{4}{*}{ Activation } & $\mathrm{HCl}$ & $50 \mathrm{~mL} / \mathrm{L}$ & Room temperature, \\
& $\mathrm{HF}$ & $40 \mathrm{~mL} / \mathrm{L}$ & $1 \sim 3 \mathrm{~min}$ \\
\multirow{5}{*}{ Ni electroplating } & $\mathrm{NiSO}_{4} \cdot 6 \mathrm{H}_{2} \mathrm{O}$ & $150-300 \mathrm{~g} / \mathrm{L}$ & \\
& $\mathrm{NiCl}_{2}$ & $45 \mathrm{~g} / \mathrm{L}$ & $50^{\circ} \mathrm{C}, 20 \mathrm{~min}, 3 \mathrm{~A} / \mathrm{dm}^{2}$ \\
& $\mathrm{H}_{3} \mathrm{BO}_{3}$ & $35 \mathrm{~g} / \mathrm{L}$ & \\
& $\mathrm{NiSO}_{4} \cdot 6 \mathrm{H}_{2} \mathrm{O}$ & $150-300 \mathrm{~g} / \mathrm{L}$ & \\
& $\mathrm{NiCl}_{2}$ & $45 \mathrm{~g} / \mathrm{L}$ & $50^{\circ} \mathrm{C}, 120 \mathrm{~min}$, \\
& $\mathrm{H}_{3} \mathrm{BO}_{3}$ & $35 \mathrm{~g} / \mathrm{L}$ & $1 \sim 5 \mathrm{~A} / \mathrm{dm}^{2}$ \\
& $\mathrm{cBN} \mathrm{particles}^{*}$ & $1-20 \mathrm{~g} / \mathrm{L}$ & \\
\hline
\end{tabular}

The surface and cross-sectional morphologies of the coatings were characterized by a scanning electron microscope (SEM). The composition of the coatings was identified by an energy dispersive spectrometer (EDS) and a X-ray diffraction (XRD).

\section{Friction and wear properties of $\mathrm{Ni}-\mathrm{cBN}$ composite coating}

The friction and wear tests for the Ni-cBN composite coatings were performed on a UMT-2 multi-function friction and wear tester under unlubricated condition. Fig. 1 shows the schematic diagram of the test machine. The spherical friction pair is a radius of $6 \mathrm{~mm}$ were fabricated by GCr15 with a hardness of HRC 62 . Tests were conducted at a sliding speed of $0.0333 \mathrm{~m} \cdot \mathrm{s}^{-1}$ and at load of $5 \sim 8$ $\mathrm{N}$ in air. Mass loss was measured with an analytical balance after ultrasonically cleaned in acetone for 3 min. The coefficient of frication was calculated by dividing the friction force which was recorded on line via torque as measured by the strain gauge. The worn surfaces of the Ni-cBN composite coatings were examined using a scanning electron microscope (SEM).

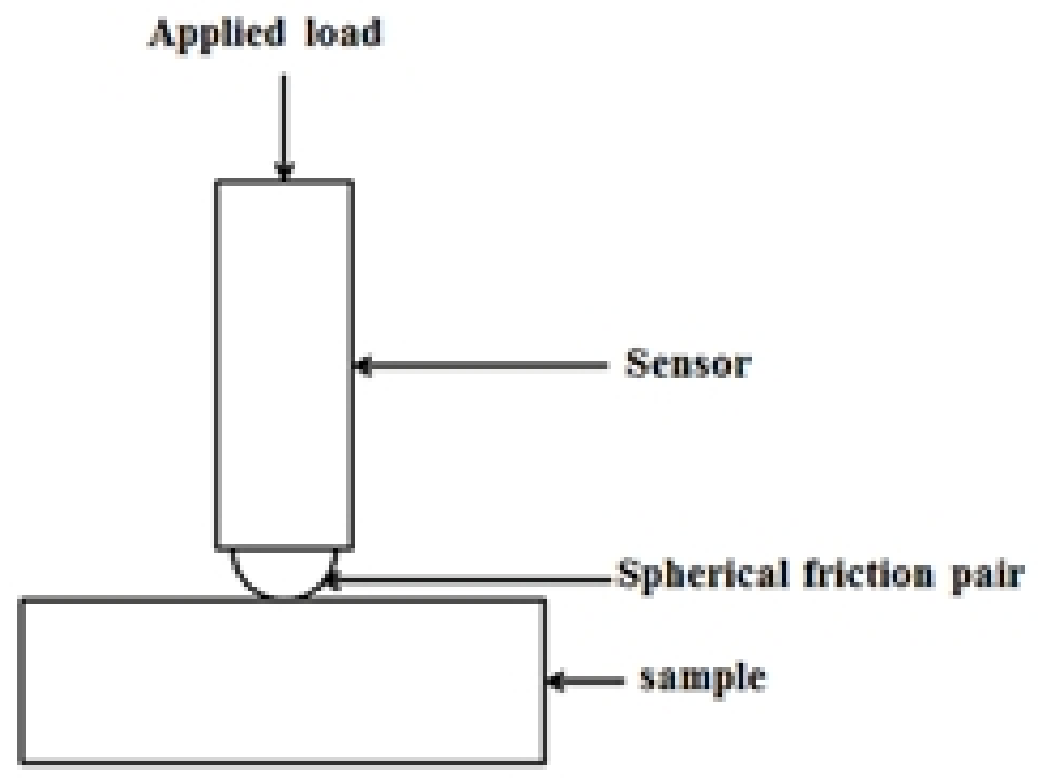

Fig. 1 Schematic diagram of UMT-2 wear tester 


\section{Results and discussion}

Fig. 2 shows a SEM image of the cubic boron nitride (cBN) particles. It can be found that the size of cBN particles ranges from $3 \mu \mathrm{m}$ to $5 \mu \mathrm{m}$.

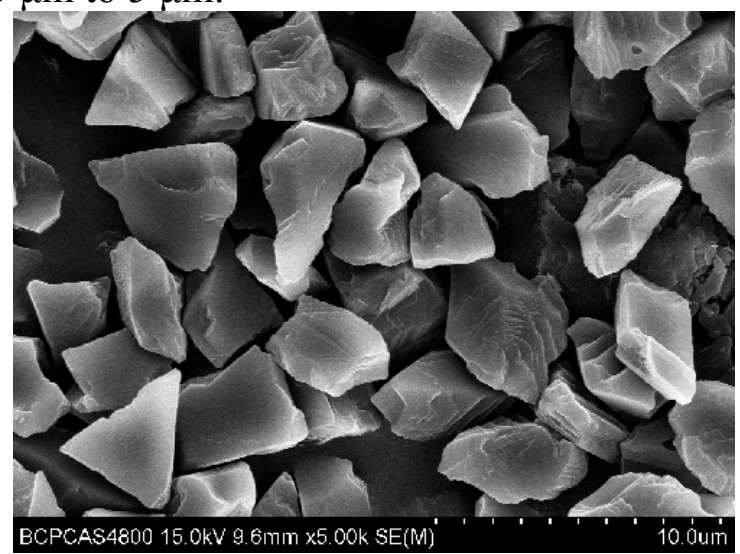

Fig. 2 The SEM image of cBN particles

The volume fractions of $\mathrm{cBN}$ in the composite coatings were calculated by the image analysis system. As shown in Table 2, the volume friction of cBN particles in Ni-cBN composite coatings decreases with the increase of current density. Fig. 3 shows the surface and cross-sectional morphology of the Ni-cBN composite coatings with $8.5 \mathrm{vol} . \% \mathrm{cBN}$ particles. It can be found that $\mathrm{cBN}$ particles are well dispersed and embedded in the nickel matrix. The micro-hardness of the composite coatings with different volume fractions of $\mathrm{cBN}$ particles are also listed in Table 2. It is evident that the Ni-cBN composite coatings reveal higher hardness then pure Ni coating. The hardness of the $\mathrm{Ni}$-cBN composite coatings increase with the increase of the volume fraction of cBN particles. As shown in Table 2, the hardness of the composite coating with 8.5 vol.\% cBN particles is the highest. Fig. 4 shows the XRD patterns of the Ni-cBN composite coatings with 8.5 vol.\%, which shows that the composite coatings are crystalline nickel and $\mathrm{cBN}$ particles.

Table. 2 Volume fraction of cBN and micro-hardness of Ni-cBN composite coatings.

\begin{tabular}{|c|c|c|}
\hline Current density $\left(\mathrm{A} \cdot \mathrm{dm}^{-2}\right)$ & $\begin{array}{l}\text { Volume fraction of } \\
\text { cBN in coatings }(\%)\end{array}$ & $\begin{array}{l}\text { Micro-hardness of } \\
\text { coatings (Hv 100) }\end{array}$ \\
\hline 1.0 & 8.5 & 625.83 \\
\hline 2.0 & 6.7 & 432.85 \\
\hline 3.0 & 3.5 & 331.12 \\
\hline 4.0 & 2.3 & 306.03 \\
\hline 5.0 & 0.3 & 212.48 \\
\hline 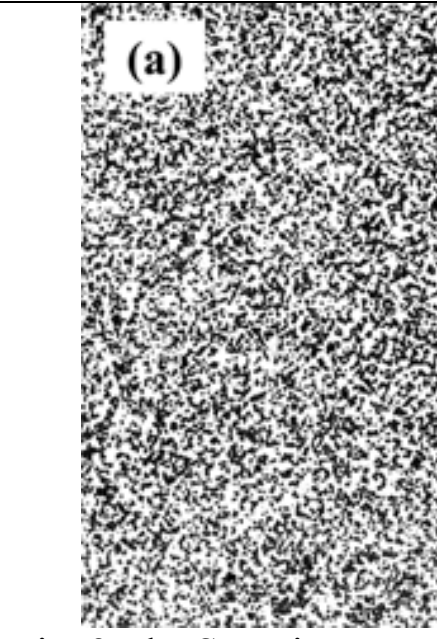 & 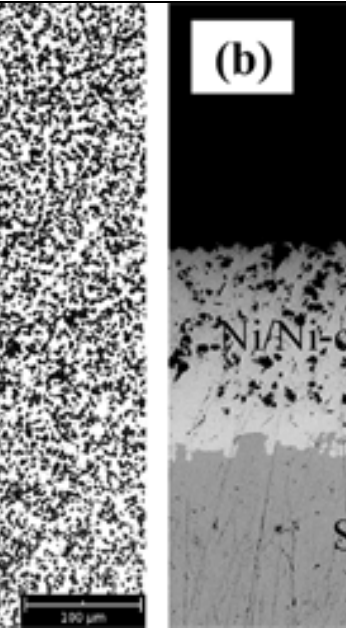 & $0 \%$ \\
\hline
\end{tabular}

Fig. 3 The SEM images of: (a) surface morphology; (b) cross-sectional morphology. 


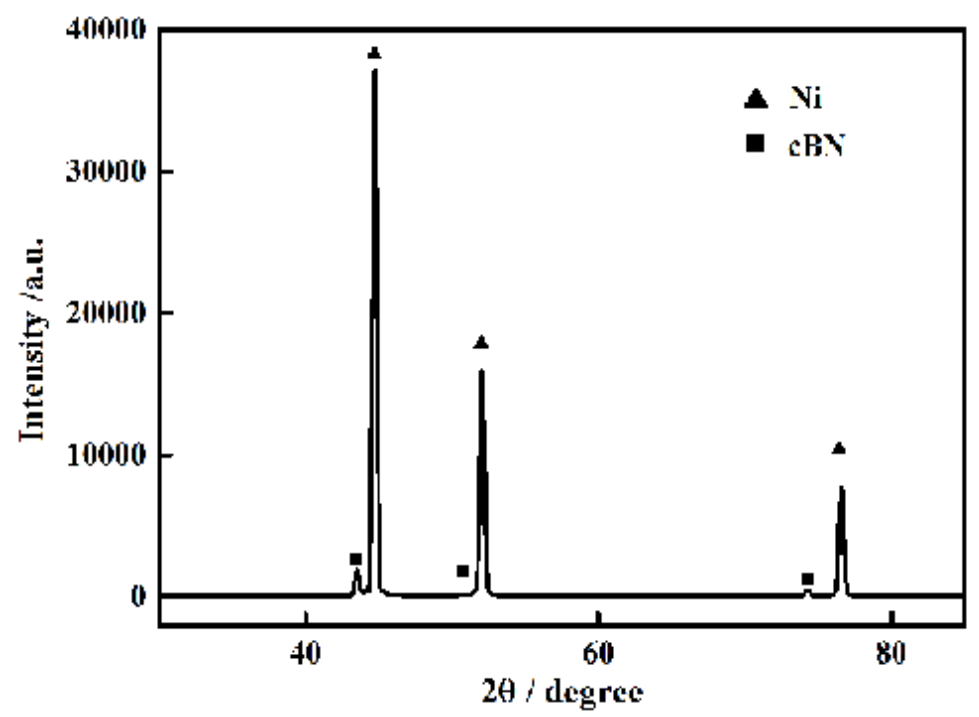

Fig. 4 XRD patterns of Ni-cBN composite coating

Fig. 5(a) shows the friction coefficients of Ni-cBN composite coatings with different $\mathrm{cBN}$ particles contents at load of $5 \mathrm{~N}$. Fig. 5(b) shows the relationship between average friction coefficient and wear rate of Ni-cBN with different $\mathrm{cBN}$ particles contents. It can be seen from Fig. 5(b) that the coefficient of friction of Ni-cBN composite coatings decreases with the increase of cBN particles content. It is indicated that an increase in surface fraction of $\mathrm{cBN}$ particles could reduce the direct contact between the nickel matrix and GCr15 steel ball. Due to self-lubrication of cBN particles, the $\mathrm{cBN}$ particles would more easily slide or roll between the mating metal surface, thus resulting in the decrease the friction coefficient of the composite coatings. In addition, Fig. 5(b) also shows the effect of volume fraction of $\mathrm{cBN}$ particles on the wear rate of the Ni-cBN composite coating. Within the range of volume fraction of $\mathrm{cBN}$ particles from 0 to $8.5 \%$, the wear rate of the Ni-cBN composite coatings shows a steadily decreasing trend with increasing volume of $\mathrm{cBN}$ particles. The favorable effects of $\mathrm{cBN}$ particles on wear resistance are attribute to their excellent mechanical properties and well dispersed in the composite coatings.

In order to understand the effect of cBN particles on the friction and wear behaviors of Ni-cBN composite coatings, the worn surface morphologies of composite with different volume fractions of cBN particles are investigated by SEM images (Fig. 6). It can be seen from Fig. 6(b) that the worn surface of pure Ni coating shows very slightly ploughed marks, which has signigicantly adhesion feature. However, less plucked but some slight ploughed marks appeared on the worn surface of Ni-cBN composite coatings(Fig. 6a), which indicates that the cBN particles in the composite can dramatically restain the adhesive wear of coatings.
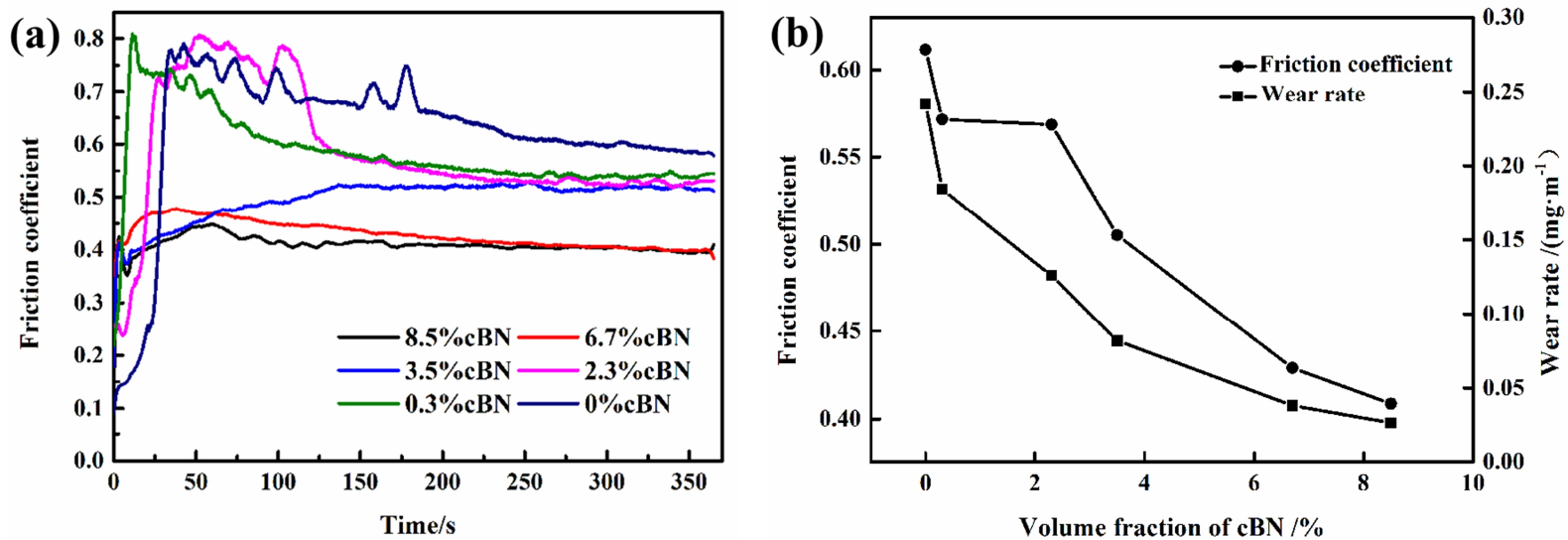

Fig. 5 (a) Variations of coefficient of friction with sliding duration; (b) Fig.7 Friction coefficient and wear rate of $\mathrm{Ni}-\mathrm{cBN}$ with different $\mathrm{cBN}$ particles contents. 

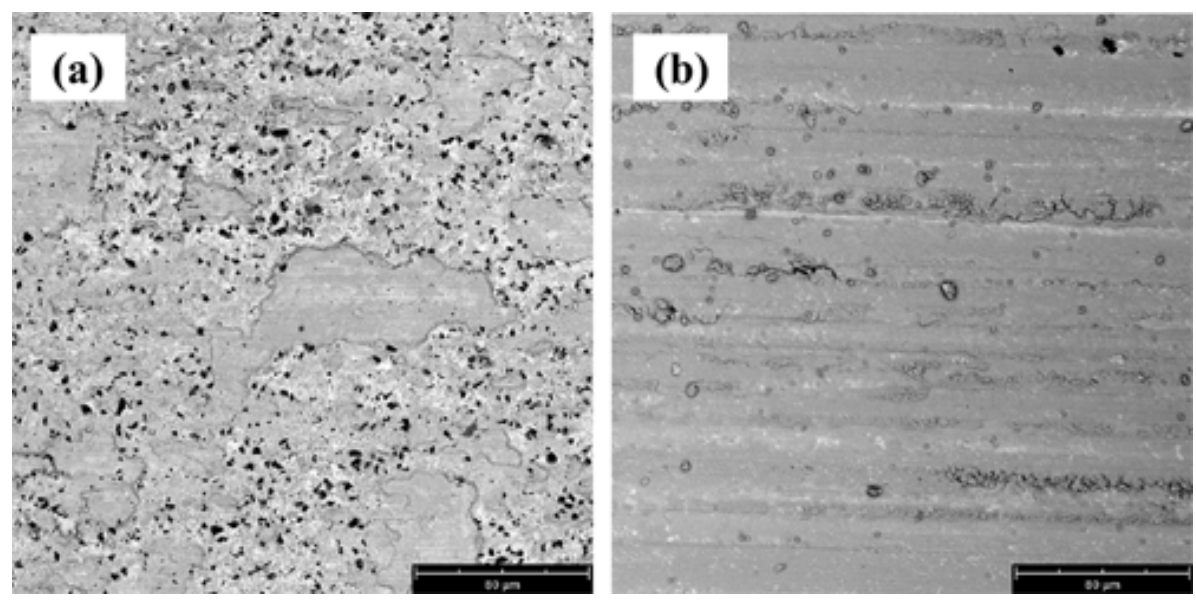

Fig. 6 Worn surface morphology of the Ni-cBN composite coatings: (a) 8.5 vol.\% of cBN particles in

Fig. 7(a) shows the friction coefficient of Ni-cBN composite coatings at different applied loads. Fig. 7(b) shows the relationship between average friction coefficient and wear rate of Ni-cBN composite coatings under different applied loads. It can be seen from Fig. 7(b) that the average coefficient of friction of Ni-cBN composite coatings increases with the increase of applied load. Moreover, the wear rate of the composite coatings incereses with increasing the applies load. The increased wear rate of the composite coatings is ascribed to the contact area increasing between friction pair and composite coating, which results from the plastic deformation of composite coating incaresing due to the increased applied load.

Fig. 8 shows worn surface morphology of the Ni-cBN composite coatings with different applied load under unlubricated condition. Through comparison between Fig. 8(a) and (b), it can be seen that the wear behavior turns mild to severe with the increases of applied load. As shown in Fig. 8(b), the worn surface of $3.5 \mathrm{vol} . \% \mathrm{cBN}$ particles composite sliding under $10 \mathrm{~N}$ clearly shows large amount of cracks are vertical to the sliding direction, which indicates that the serious fatigue wear is the main wear mechanism of Ni-cBN composite coatings when sliding under high load. It can be inferred that larger area of friction surface of composite will flake away if the load further increases and the material will be seriously damaged.
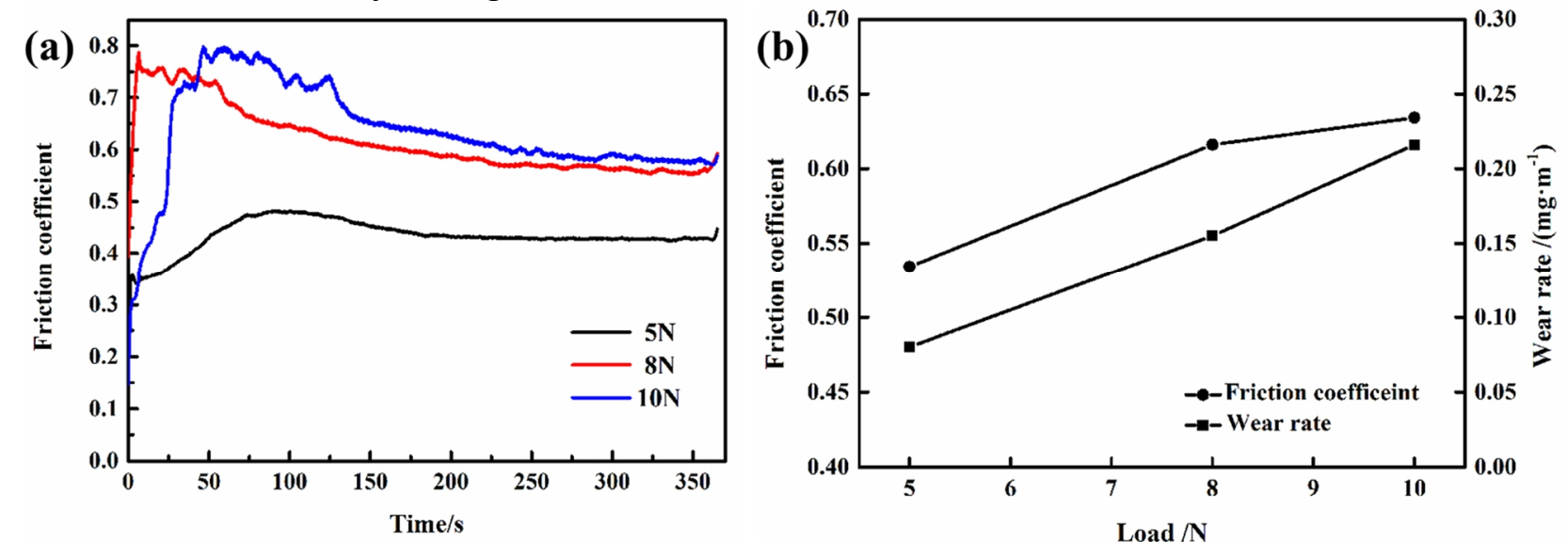

Fig. 7 (a) Variations of coefficient of friction with sliding duration; (b) Friction coefficient and wear rate of $\mathrm{Ni}-\mathrm{cBN}$ with different applied loads. 

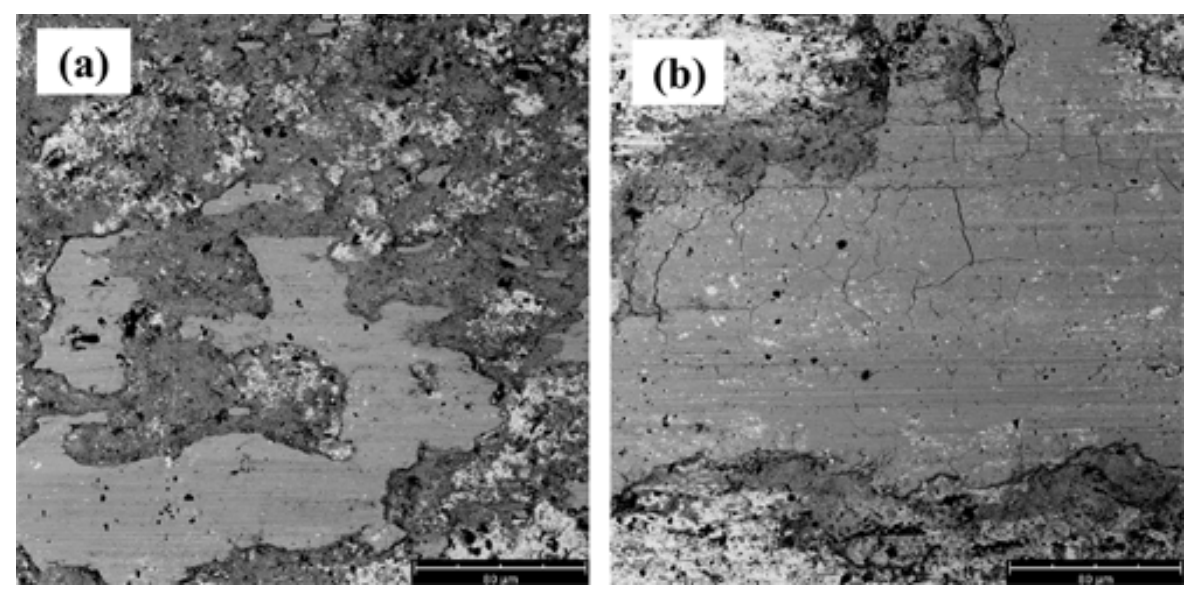

Fig. 8 Worn surface morphology of the Ni-cBN composite coatings: (a) $5 \mathrm{~N}$; (b) $10 \mathrm{~N}$.

\section{Conclusions}

Ni-cubic boron nitride (cBN) composite coatings have been successfully deposited on a titanium alloy substrate by electro-deposition technology. The cBN particles can be well dispersed and embedded in the nickel matrix. The results demonstrate that Ni-cBN composite coatings exhibit higher wear resistance and lower friction coefficient than pure $\mathrm{Ni}$ coating under unlubricated condition. Due to self-lubrication of $\mathrm{cBN}$ particles, the friction coefficient of the composite coatings decreases with increasing the volume friction of $\mathrm{cBN}$ particles. The wear rate of the composite coatings exhibits decrease with the volume fraction of $\mathrm{cBN}$ particles increasing from 0 to $8.5 \%$. With the applied load increasesing from $5 \mathrm{~N}$ to $10 \mathrm{~N}$, friction coefficient and the wear rate of the composite coatings increases

The favorable effects of $\mathrm{cBN}$ particles on the tribological parameters attribute to their excellent mechanical properties. The cBN particles may be released from the matrix onto the metal surface during the experiment, serving as spacers, which prevent the asperities from contacting. Therefore, the tribological properties of the composites and coating with $\mathrm{cBN}$ particles are significantly improved.

\section{References}

[1] Jin L, Li P, Zhou H, et al. Improving thermal insulation of TC4 using YSZ-based coating and SiO 2 aerogel[J]. Progress in Natural Science: Materials International, 2015.

[2] Xiankai M, Jianzhong Z, Shu H, et al. Residual Stress Relaxation and Fatigue Properties of TC4 Titanium Alloy Induced by Warm Laser Peening under High-Cycle Fatigue[J]. RARE METAL MATERIALS AND ENGINEERING, 2015, 44(5): 1185-1190.

[3] Li G R, Li Y M, Wang F F, et al. Microstructure and performance of solid TC4 titanium alloy subjected to the high pulsed magnetic field treatment[J]. Journal of Alloys and Compounds, 2015, 644: 750-756.

[4] Q Y Wang, Z M Ge, Y B Zhou, Titanium Alloys in Aeronautical Application [M], Shanghai Science Press, Shanghai, 1985, pp.68-69.

[5] Salazar P, Rico V, Rodríguez-Amaro R, et al. New Copper wide range nanosensor electrode prepared by physical vapor deposition at oblique angles for the non-enzimatic determination of glucose[J]. Electrochimica Acta, 2015, 169: 195-201.

[6] Frey H. Chemical Vapor Deposition (CVD)[M]. Handbook of Thin-Film Technology. Springer Berlin Heidelberg, 2015: 225-252.

[7] Cheng C F, Hsueh H Y, Lai C H, et al. Nanoporous gyroid platinum with high catalytic activity from block copolymer templates via electroless plating[J]. NPG Asia Materials, 2015, 7.

[8] Zhang J, Liu L, Liang Y, et al. Enhanced precipitation of cyanide from electroplating wastewater via self-assembly of bimetal cyanide complex[J]. Separation and Purification Technology, 2015. 
[9] Chen X H, Chen C S, Xiao H N, et al. Corrosion behavior of carbon nanotubes-Ni composite coating[J]. Surface and Coatings Technology, 2005, 191(2): 351-356.

[10] Sabzi M, Mirabedini S M, Zohuriaan-Mehr J, et al. Surface modification of TiO 2 nano-particles with silane coupling agent and investigation of its effect on the properties of polyurethane composite coating[J]. Progress in Organic Coatings, 2009, 65(2): 222-228.

[11] Huang Y S, Zeng X T, Annergren I, et al. Development of electroless NiP-PTFE-SiC composite coating[J]. Surface and Coatings Technology, 2003, 167(2): 207-211.

[12] Qu N S, Chan K C, Zhu D. Pulse co-electrodeposition of nano Al 2 O 3 whiskers nickel composite coating[J]. Scripta Materialia, 2004, 50(8): 1131-1134.

[13] Lu S P, Kwon O Y. Microstructure and bonding strength of WC reinforced Ni-base alloy brazed composite coating[J]. Surface and Coatings Technology, 2002, 153(1): 40-48.

[14] Zhou H, Du N, Zhu L, et al. Characteristics investigation of Ni-diamond composite electrodeposition[J]. Electrochimica Acta, 2015, 151: 157-167.

[15] Teii K, Matsumoto S. Impact of low-energy ions on plasma deposition of cubic boron nitride[J]. Thin Solid Films, 2015, 576: 50-54.

[16] Thepsonthi T, Özel T. Experimental and finite element simulation based investigations on micro-milling Ti-6Al-4V titanium alloy: effects of cBN coating on tool wear[J]. Journal of Materials Processing Technology, 2013, 213(4): 532-542.

[17] Uhlmann E, Fuentes J A O, Keunecke M. Machining of high performance workpiece materials with CBN coated cutting tools[J]. Thin solid films, 2009, 518(5): 1451-1454. 